\title{
Total Matrix Metalloproteinase-2 and Prostaglandin E2 as Potential Biomarkers in Iraqi AML Patients
}

\author{
Hassnien S. AL- Hashemi ${ }^{1}$, Sabah A. Hameid A. Rahman ${ }^{2}$, Zeyad A. Shabeeb ${ }^{3}$ \\ ${ }^{1}$ Assistant Lecturer, MSc Clinical Immunology, National center of Hematology, Mustansiriyah University, Iraq, \\ ${ }^{2}$ Professor, PhD Clinical Physiology, College of Science, Mustansiriyah University, Iraq, ${ }^{3}$ Assistant Professor, PhD \\ Clinical Immunology, National center of Hematology, Mustansiriyah University, Iraq
}

\begin{abstract}
Acute Myeloid Leukemias (AMLs) are rare but extremely malignant neoplasms that are liable for a big amount of fatalities associated with cancer. Acute myeloid leukemia (AML) results from accumulation of abnormal myeloblasts, most commonly in the bone marrow, leading to bone marrow failure and death. The present study was carried out to evaluate MMP-2 and PG E2 in sera and of (50) AML Iraqi patients, In addition to control group involving (50) matched apparently healthy subjects. This study was done in the National center of hematology, Department of biology at AL-Mustansiyria University, Baghdad Medical City since January 2019 to June 2020. The aim of study was to determine the level of total Matrix Metalloproteinase 2 and prostaglandin E2 in patients with AML by ELISA. and study the impact of these parameters on the pathogenesis of disease, also predict the AML and how the parameters correlated with stages and severity of disease and responsiveness to therapy. Conclusion: MMP-2 decreased and elevated of PGE2 in the serum of AML patients .
\end{abstract}

Keywords: AML, MMP-2,PGE2, ELISA, Matrix metalloproteinase, prostaglandin E2.

\section{Introduction}

Matrix Metalloproteinase-2 (MMP-2) and Prostaglandin E2 (PG E2) Roles in AML: The Matrix Metalloproteinase (MMP) family was discovered from studies of collagen breakdown during tadpole morphogenesis ${ }^{(15)}$. Matrix Metalloproteinase (MMP) are now known as a family of 24 homologous $\mathrm{Zn} 2+$ -dependent proteinases essential for normal extracellular matrix (ECM) breakdown, growth factor secretion and cytokine activation during wound healing, tissue remodeling, embryogenesis, neovascularisation, cell migration, and immune response regulation ${ }^{(33,26)}$.

\footnotetext{
Corresponding Author:

Hassnien S. AL- Hashemi

National Center of Hematology, Mustansiriyah

University, Baghdad, Iraq

e-mail: hassnhashmi@gmail.com

Phone Number: 009647702580096
}

MMP-2, also called gelatinase A, promotes the invasion and metastasis of cancer cells by destroying the collagen IV, V and X present in the ECM and basement membranes $^{(16)}$.

MMPs play an significant role in the development of hematologic malignancies. Most of the research centered on the role of MMP-2 in leukemia gelatinases. Shows the role of hematopathogenesis MMPs in hematological disorder. This explains the role of MMPs and their inhibitors in hematological malignancies including MDS, AML and chronic myeloid leukemia ${ }^{(35)}$.Higher angiogenesis was observed in patients with acute leukemia, which vanished if complete hematological remission was achieved ${ }^{(10,27,28)}$. The increased vessel density found in the AML bone marrow correlated with the expression of the vascular endothelial growth factor (VEGF) ${ }^{(7)}$; Hence a role is hypothesized for other angiogenic factors such as matrix metalloproteinases. No expression of MMP-2 could be detected in normal mononuclear bone marrow cells ${ }^{(19)}$. Matrigel may be invaded by primary AML blasts, depending on their 
MMP-2 expression(31). MMP-2 expression may also contribute to the increased vessel density observed in AML patients' bone marrow during diagnosis by promoting in vitro cell migration ${ }^{(10)}$. Abnormal expression levels of MMP-2 were observed in AML patients and myelodysplastic syndrome (MDS) ${ }^{(32)}$. MMP-2 has a low level of expression in myeloid cells; MMP-9 is found primarily in T lymphocytes, malignant B lymphocytes and mature myeloid and monocytic cells ${ }^{(1)}$.

Prostaglandin E2 also called dinoprostone belongs to the family of lipid hormone-like signaling eicosanoids with essential inflammatory and physiological functions ${ }^{(8)}$.Most eicosanoid molecules are made from the enzymatic modification of arachidonic acid (AA), a polyunsaturated fatty acid esterified in mammalian cell membrane phospholipids ${ }^{(4)}$. PG E2 is produced omni presently and acts as autocrine and paracrine lipid mediators to maintain local homeostasis in the body. Both level and profile of prostaglandin (PG) production change drastically during an inflammatory response. The production of PG in uninflamed tissues is normally very low but increases immediately in acute inflammation before leukocyte recruitment and immune cell infiltration (29). Biosynthesis of prostaglandin is blocked by nonsteroidal anti-inflammatory drugs (NSAIDs), which inhibit the action of either cyclooxygenases or both. In addition to their role in homeostasis, prostanoids can modulate immune responses and contribute to tumor initiation, vascularization and chronic inflammation ${ }^{(30)}$.

The mechanisms that underlie PGE2's effects on cancer growth are, elusive. In a recent review, Zelenay et al. presented first direct evidence that PGE2 could promote tumor growth by evading immune attacks in melanoma models for murine tumor transplantation ${ }^{(36)}$.

Tumor derived prostaglandin E2 (PGE2) plays a major role in suppressing the activity and survival of CTLs in patients undergoing immunotherapy for cancer. PGE2 have also been shown to suppress survival of CTLs, interferon type I production and in vitro cytotoxicity Previous evidence shows that exhausted CTLs increased the expression of certain inhibitory receptors including the PGE2 receptors EP4 and EP2 using profiling of the entire genome expression ${ }^{(25)}$. In AML blasts, PGE2 has been shown to be upregulated as opposed to mononuclear blood cells ${ }^{(13)}$. It has elevated serum levels of prostaglandin E2 in patients with acute lymphoid leukemia. Upon full remission with induction chemotherapy, the elevated plasma prostaglandin E2 levels decreased significantly ${ }^{(22)}$.

\section{Method}

The study was conducted on 50 Iraqi patients with acute myeloid leukemia and 50 matched healthy looking subject. The age range of the patients within 17-80 years. This study was done in the National center of hematology, Department of biology at AL-Mustansiyria University, Baghdad Medical City since January 2019 to June 2020 . Each patient was subjected to physical examination done by specialist and illness -information related to this research were obtained.

This assay employs the quantitative sandwich enzyme immunoassay technique (ELISA) (for Total MMP-2 and PG E2 in serum, the kits was used from R \& D Systems,USA.

\section{Result and Discussion}

The present study demonstrated a statistically significant decreased level of Matrix Metalloproteinase 2 in patients with AML as compared with control subjects $(p<0.01)$ Table (1) Figure (1))the current findings were agreed with (Lin et al., 2002) who show there was lower level of MMP-2 in the AML patient Also another report in Egypt $^{(3)}$ that mentioned there were decrease in the level of MMP-2 in AML patients.

In Iranian study ${ }^{(6)}$ who showed the MMP-2 levels in AML patient were not much higher as compared to normal bone marrow (BM) donor.

An association of MMP-2/-9 expression with invasive activity of leukemic cells in acute lymphoblastic leukemia (ALL) and acute myelogenous leukemia (AML) has been recorded earlier. In addition, MMP-2/9 seems to have prognostic effect in AML ${ }^{(12)}$.Another study that measured the expression of MMP-2 in the Amyloid precursor protein (APP) which is prognostic significance in AML, the expression of MMP-2 revealed decreasing in the patients ${ }^{(17)}$.

Our finding Disargree with ${ }^{(6)}$ because they were used Bone marrow CD34 to measured MMP-2 in the blast cell and also Real time PCR technique while present study use Enzyme linked Immunosorbent Assay (ELISA). 
Table (1): Matrix Metalloproteinase 2 (Total MMP-2) concentration among patient and control in serum. $* *(\mathbf{P}<\mathbf{0 . 0 1})$

\begin{tabular}{|l|c|c|c|c|c|}
\hline Total MMP-2 & No. & Mean \pm se & Range & P-value & T-test Value \\
\hline Patients & 50 & $3.815 \pm 0.72$ & $0.122-15.1$ & 0.000 & $-7.49 * *$ \\
\hline Control & 50 & $10.636 \pm 0.558$ & $7.3-18.9$ & & \\
\hline
\end{tabular}

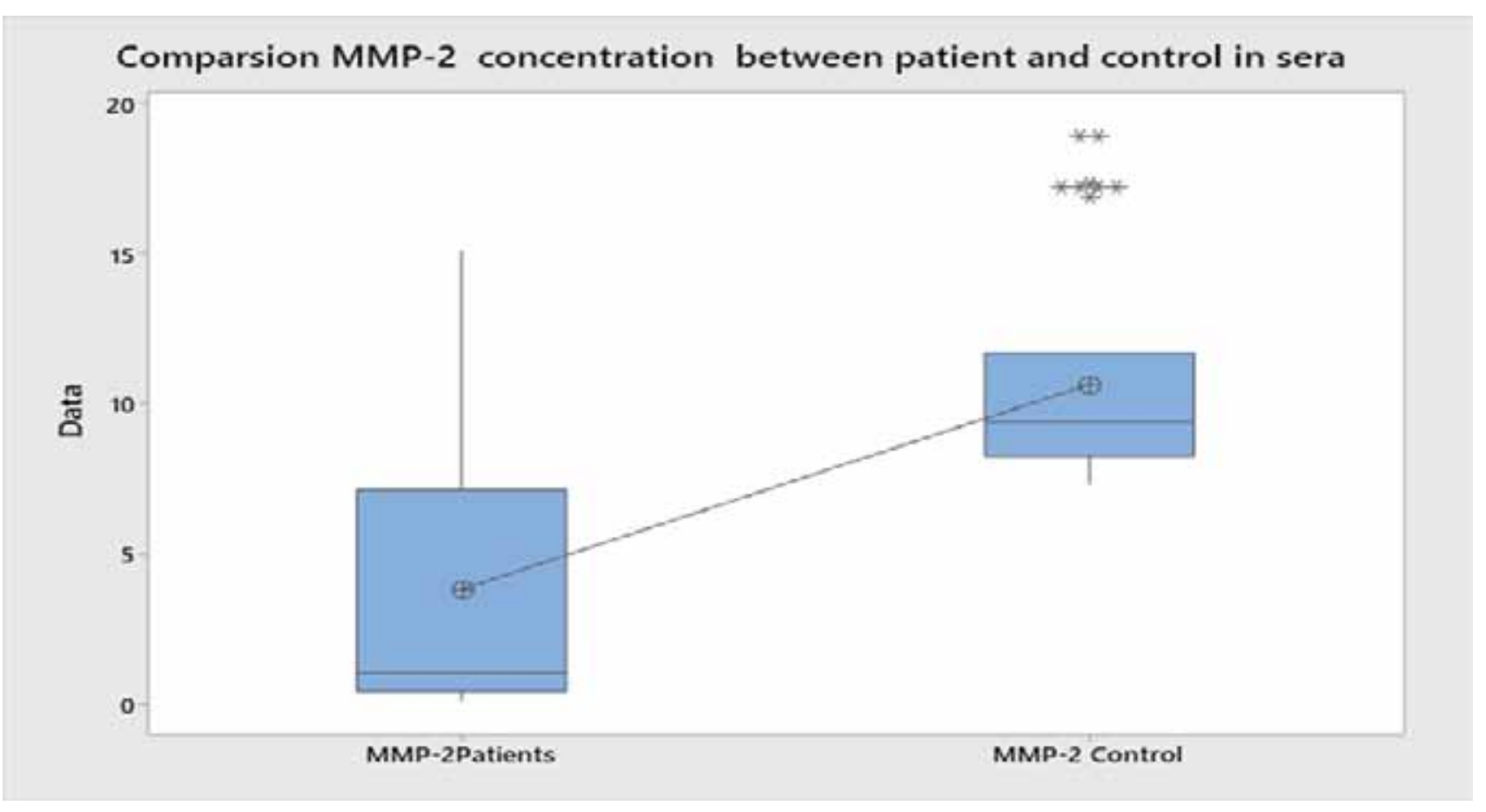

Figure (1) Matrix Metalloproteinase 2 (Total MMP-2) concentration among patient and control

The concentration of prostaglandin E2 in AML patient serum was $(339.5 \pm 60.8)$ while the concentration of prostaglandin E2 of the healthy control serum were $(19.95 \pm 0.558)$ there were a highly significant differences between patient and control $((\mathbf{P}<\mathbf{0 . 0 1})$. the present result was agree with previous reports $(\mathbf{9 , 2 4 , 3 0 )}$. Table (2) (Figure (2)

The current result were agree with ${ }^{(22)}$ who were showed there was increase in the level of PG E2 in the AML children compared with control .
Importantly, similar results were obtained ${ }^{(15)}$ who were show >100-fold PGE2 more than healthy control

The tumor-promotive activity of PGE2 regulated by A vascular endothelial growth factor (VEGF) or cyclic monophosphate-dependent adenosines (cAMP) pathway which induces an activation of the proliferation of the cancer cell and has anti-apoptotic effects in various tissues ${ }^{(34)}$.

Table (2): Prostaglandin E2 (PGE2) concentration among patient and control in serum . $* *(P<0.01)$

\begin{tabular}{|l|c|c|c|c|c|}
\hline Total PGE2 & No. & Mean \pm se & Range & P-value & T - test Value \\
\hline Patients & 50 & $339.5 \pm 60.8$ & $45.3-1585.9$ & 0.000 & $5.25^{* *}$ \\
\hline Control & 50 & $19.95 \pm 0.558$ & $2.21-40.01$ & & \\
\hline
\end{tabular}




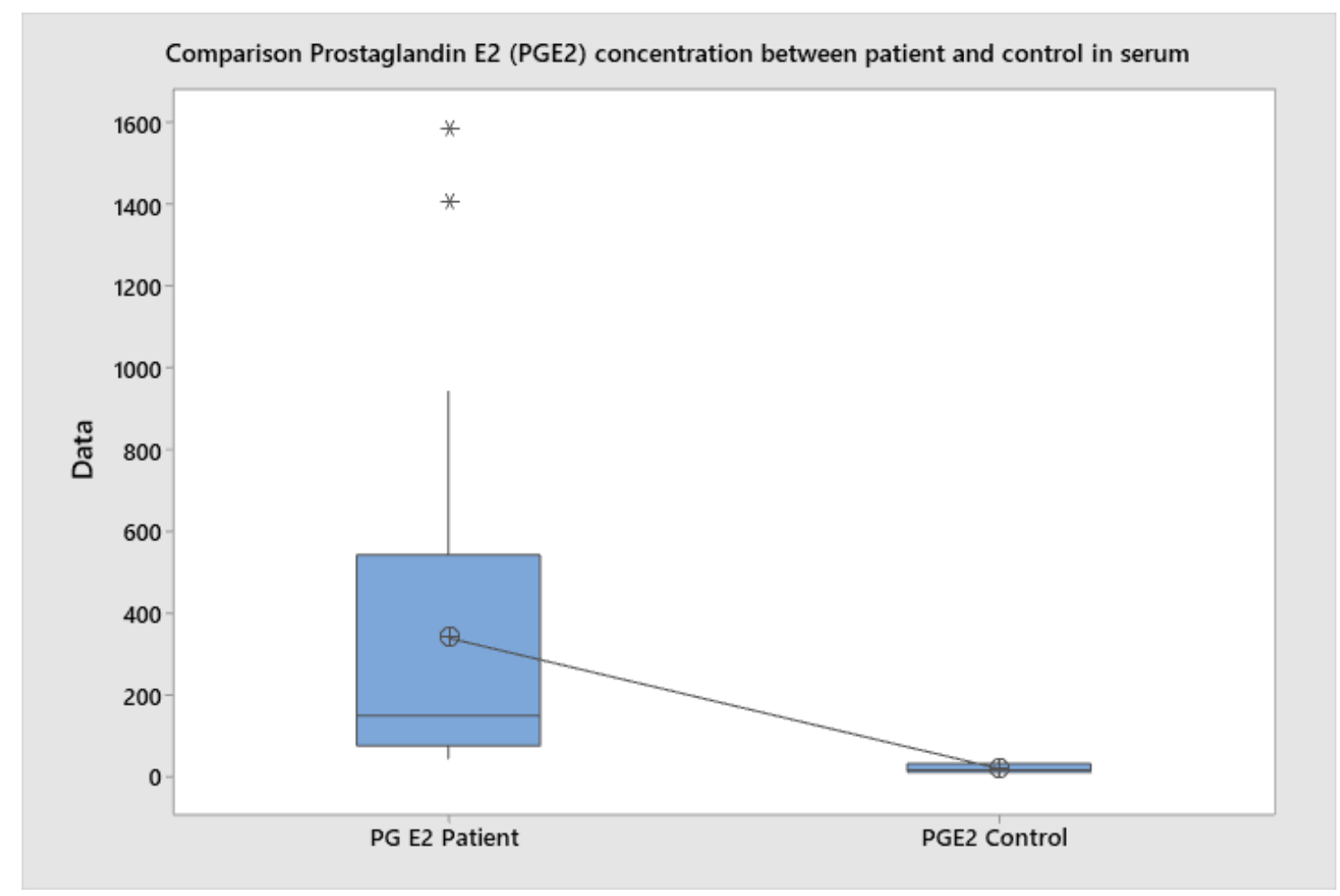

Figure (2) Prostaglandin E2 (PGE2) concentration among patient and control in serum

In the course of current analysis, we examined serum samples of a total of 50 patients with Newly AML(8\%) $(n=4)$, Partial remission AML $(22 \%)(n=11)$, AML in complete remission (10\%) $(n=5)$, Refractory (36\%) $(n$ $=18)$, and Relapse(24\%) $(n=12)$.

The level of Matrix Metalloproteinase 2 (MMP-2) were decreased in the relapse $(2.23 \pm 0.8 \mathrm{ng} / \mathrm{ml})$, refractory $(3.37 \pm 1.41 \mathrm{ng} / \mathrm{ml})$,partial remission $(3.57 \pm 1.54 \mathrm{ng} /$ $\mathrm{ml})$ and newly diagnosis patients $(2.03 \pm 1.55 \mathrm{ng} / \mathrm{ml})$ compared with healthy control $(10.636 \pm 0.558 \mathrm{ng} / \mathrm{ml})$ Table (3). The present data agree with ${ }^{(32)}$ who were compared between AML-treated patients with intensive chemotherapy, the expression of MMP-2 was not different in resistant cases and in patients with complete remission

MMP-2 pretreated lower than level of MMP-2 post treated agreed with ${ }^{(3)}$ However ${ }^{(23)}$ who revealed the patient with acute lymphoblastic leukemia (ALL) patients, they found MMP-2 level were higher as compared to BM donors.
The pervious study were measured the MMP9 level before treated with chemotherapy and after treatment they showed decrease in the level of matrix metalloproteinase in the patient with lung cancer ${ }^{(11)}$.

While the concentration of Prostaglandin E2 were much higher in relapse patient $(498 \pm 211 \mathrm{pg} / \mathrm{ml})$ and also high in partial remission patients (347 \pm 132$)$ and the level of prostaglandin E2 in refractory (291.2 \pm 86.4$)$,complete remission $(301 \pm 86.4)$ and newly diagnosis $(246 \pm 140)$ were higher than human control (19.95 \pm 0.558$)$ Table (3). Although there is a scarcity of researches that is similar to the current research the current findings were agreed with ${ }^{(2)}$ elevate of PGE2 that will lead to increases the activation of Tregs and participates in the development of Myeloid derived suppresser cell (MDSC) Such cells infiltrate the microenvironment of the tumor and dampen the immune response of the tumor by inhibiting the function of the T-cell effector, which in turn hampers immunity against cancer ${ }^{(24)}$. 
Table (3): AML patient Among All parameters and stages of disease

\begin{tabular}{|l|c|c|c|c|c|c|}
\hline Parameters & Control & Newly(n=4) & $\begin{array}{c}\text { Partial (PR) } \\
(\mathbf{n}=\mathbf{1 1})\end{array}$ & $\begin{array}{c}\text { Complete (CR) } \\
(\mathbf{n}=\mathbf{5})\end{array}$ & $\begin{array}{c}\text { Refractory } \\
(\mathbf{R F})(\mathbf{n}=\mathbf{1 8})\end{array}$ & $\begin{array}{c}\text { Relapse (R) } \\
(\mathbf{n}=\mathbf{1 2})\end{array}$ \\
\hline MMP-2 \pm SE & $10.636 \pm 0.558$ & $2.03 \pm 1.55$ & $3.57 \pm 1.54$ & $8.93 \pm 1.89$ & $3.37 \pm 1.41$ & $2.23 \pm 0.8$ \\
\hline PGE-2 & $19.95 \pm 0.558$ & $246 \pm 140$ & $347 \pm 132$ & $301 \pm 86.4$ & $291.2 \pm 86.4$ & $498 \pm 211$ \\
\hline
\end{tabular}

\section{Conclusion}

The mean level of Matrix Metalloproteinase 2 (Total MMP-2) concentration serum was a statistically decreased in patients of AML as compared with control subjects $(\mathrm{p}<0.05)$, furthermore The levels of Prostaglandin E2 (PGE2) concentration were significantly increased in patients with AML compared with healthy subjects $(339.5 \pm 60.8 \mathrm{pg} / \mathrm{ml}$ vs. $19.95 \pm 0.55 \mathrm{pg} / \mathrm{ml}) \quad(\mathrm{p}<0.05)$. the level of MMP-2 deceased and PG-E2 elevated with AML stages that were consider MMP-2 and PG-E2 was indictor for progression of AML disease .

\section{Conflict of Interest: None}

Funding: Self

Ethical Clearance: Not required

1. Amin A. A., Bagheri, M., Zibara, K., MalekiBehzad, M., \& Shahrabi, S. Expression and activity of matrix Metalloproteinases in leukemia.Journal of Pediatric Hematology/Oncology, 2019. 41(2), 87-95.https:// doi.org/10.1097/mph.0000000000001386.

2. Andreeff $M$. Novel Targets in the AML Microenvironment. Clinical Lymphoma Myeloma and Leukemia, 2017. 17, S208-S213. doi:10.1016/j. clml.2017.08.103

3. Aref, S., Osman, E., Mansy, S., Omer, N., Azmy, E., Goda, T., \& El-Sherbiny, M. Prognostic relevance of circulating matrix metalloproteinase-2 in acute myeloid leukaemia patients. Hematological Oncology, 2007. 25(3), 121-126. doi:10.1002/ hon. 817

4. Black HS, Rhodes LE. Potential benefits of omega-3 fatty acids in non-melanoma skin cancer. Journal of clinical medicine. $2016 \mathrm{Feb} ; 5(2): 23$.

5. Carter BZ, Mak PY, Wang X, Tao W, Ruvolo V, Mak D, Mu H, Burks JK, Andreeff M. An ARCRegulated IL1 $\beta /$ Cox-2/PGE2/ $\beta$-Catenin/ARC Circuit Controls Leukemia-Microenvironment Interactions and Confers Drug Resistance in AML. Cancer research. 2019 Mar 15;79(6):1165-77.
6. Chaudhary Ak., Chaudhary S., Ghosh K., Chandrakala Shanmukaiah C., Nadkarni AH. Secretion and Expression of Matrix Metalloproteinase-2 and 9 from Bone Marrow Mononuclear Cells in Myelodysplastic Syndrome and Acute Myeloid Leukemia. Asian Pac J Cancer Prev, 201617 (3), 1519-1529. doi.org/10.7314/ APJCP.2016.17.3.1519

7. de Bont ESJM, Rosati S, Jacobs S, Kamps WA, Vellenga E. Increased bone marrow vascularization in patients with acute myeloid leukaemia: a possible role for vascular endothelial growth factor.Br $\mathrm{J}$ Haematol 2001;113:296-304.

8. Dennis, E. A., \& Norris, P. C. Eicosanoid storm in infection and inflammation. Nature Reviews. Immunology, 2015. 15, 511-523.

9. Dharmapuri G, Doneti R, Philip GH, Kalle AM. Celecoxib sensitizes imatinib-resistant K562 cells to imatinib by inhibiting MRP1-5, ABCA2 and ABCG2 transporters via Wnt and Ras signaling pathways. Leuk Res 2015; 39: 696-701.

10. Di Raimondo F, Palumbo GA, Azzaro MP, Giustolisi R. Angiogenesis in acute myeloid leukemia. Blood; 2000, 96:3656.

11. Ertan E., Soydinc, H., Yazar, A., Ustuner, Z., Tas, F., \& Yasasever, V. Matrix metalloproteinase-9 decreased after chemotherapy in patients with nonsmall cell lung cancer. Tumori, 2011. 97(3), 286289. https://doi.org/10.1700/912.10023

12. Feng S., Cen, J., Huang, Y., Shen, H., Yao, L., Wang, Y., \& Chen, Z. Matrix metalloproteinase-2 and -9 secreted by leukemic cells increase the permeability of blood-brain barrier by disrupting tight junction proteins. PloS one, 2011. 6(8), e20599. https://doi. org/10.1371/journal.pone.0020599

13. Fiancette, R.; Vincent, C.; Donnard, M.; Bordessoule, D.; Turlure, P.; Trimoreau, F.; Denizot, Y. Genes encoding multiple forms of phospholipase $\mathrm{A}(2)$ are expressed in immature forms of human leukemic blasts. Leukemia, 2009. 23, 1196-1199. 
14. Gentles AJ, Plevritis SK, Majeti R, Alizadeh AA. Association of a leukemic stem cell gene expression signature with clinical outcomes in acute myeloid leukemia. JAMA; 2010. 304(24):2706-271

15. Gross, J., and Lapiere, C.M. Collagenolytic activity in amphibian tissues: a tissue culture assay. Proc Natl Acad Sci U S A, 1962. 48: 1014-1022.

16. Iurlaro M, Loverro G, Vacca A, Cormio G, Ribatti D, Minischetti M, Ria R.,Bruno M.,Selvaggi L. Angiogenesis extent and expression of matrix metalloproteinase- 2 and -9 correlate with upgrading and myometrial invasion in endometrial carcinoma. Eur J Clin Invest. 1999; 29(9):793 \pm 801 . doi: 10.1046/j.1365-2362. 00532.x PMID: 10469168

17. Jiang, L., Yu, G., Meng, W., Wang, Z., Meng, F., \& Ma, W. Overexpression of amyloid precursor protein in acute myeloid leukemia enhances extramedullary infiltration by MMP-2. Tumor Biology, 2012. 34(2), 629-636. doi:10.1007/ s13277-012-0589-7

18. Jung N, Dai B, Gentles AJ, Majeti R, Feinberg AP. An LSC epigenetic signature is largely mutation independent and implicates the HOXA cluster in AML pathogenesis. Nat Commun; 2015. 6:8489.

19. Klein S.L., Flanagan K.L. Sex differences in immune responses. Nat. Rev. Immunol. 2016. 16:626-638. doi: 10.1038/nri.2016.90.

20. Klein, G., Vellenga, E., Fraaije, M. ., Kamps, W. ., \& de Bont, E. S. J. M. The possible role of matrix metalloproteinase (MMP)-2 and MMP-9 in cancer, e.g. acute leukemia. Critical Reviews in Oncology/ Hematology, 2004. 50(2), 87-100. doi:10.1016/j. critrevonc.2003.09.001

21. Bhat GM. A child with acute lymphoblastic leukemia (ALL) presenting with symptomatic hypercalcemia and multiple osteolytic lesions. Indian Journal of Medical and Paediatric Oncology. 2007 Jul 1;28(3):46.

22. Lee YH, Lim YJ, Bae JJ, Kim JY, Shin JH. Hypercalcemia and extensive osteolytic lesion with increased plasma prostaglandin E2 level in a child with acute lymphoblastic leukemia. The Korean Journal of Hematology. 2007 Dec 1;42(4):433-8.

23. Lin LI, Lin DT, Chang CJ, Lee CY, Tang JL, Tien HF. Marrow matrix metalloproteinases (MMPs) and tissue inhibitors of MMP in acute leukaemia: potential role of MMP-9 as a surrogate marker to monitor leukaemic status in patients with acute myelogenous leukaemia. $\mathrm{Br} \mathrm{J}$ Haematol. 2002. 117(4):835-841. doi:10.1046/j.13652141.2002.03510.x

24. Loew, A., Köhnke, T., Rehbeil, E., Pietzner, A., \& Weylandt, K.-H. A Role for Lipid Mediators in Acute Myeloid Leukemia. International Journal of Molecular Sciences, 2019. 20(10), 2425. doi:10.3390/ijms20102425

25. Miao J., Lu X., Hu Y., Piao C., Wu X., Liu X., Huang C., Yue Wang, Li D., Liu J. Prostaglandin E2 and PD-1 mediated inhibition of antitumor CTL responses in the human tumor microenvironment .Oncotarget. 2017 Oct 2017. 27; 8(52): 8980289810.

26. Nagase, H., Visse, R., and Murphy, G. Structure and function of matrix metalloproteinases and TIMPs. Cardiovasc Res. 2006. 69(3): 562-573. doi: 10.1016/j.cardiores.2005.12.002.

27. Padró T, Berdel WE, Büchner T, Mesters RM. Angiogenesis and anemia in acute myeloid leukemia. Blood; 2000a, 96:3656-7.

28. Padró T, Ruiz S, Bieker R, Bürger H, Steins M, Kienast J, Büchner T, Berdel WE, Mesters RM. Increased angiogenesis in the bone marrow of patients with acute myeloid leukemia. Blood, 2000b, 95:2637-44.

29. Ricciotti, E., \& FitzGerald, G. A. Prostaglandins and Inflammation. Arteriosclerosis, Thrombosis, and Vascular Biology, 2011. 31(5), 986-1000. doi:10.1161/atvbaha.110.207449

30. Snouwaert J.N., Jania L., Nguyen M.T., Dontu P., Besse J., Akla B., Ferré P.J. and Koller B.H. Prostaglandin E2 produced by tumor cells or by the host tumor microenvironment is not completely abolished by aspirin or celecoxib and limits the ability of the host immune system to control tumor growth. AACR. 2019.79(17),503 .

31. Sawicki G, Matsuzaki A, Janowska-Wieczorek A. Expression of theactive form of MMP-2 on the surface of leukemic cells accounts for their in vitro invasion. J Cancer Res Clin Oncol; 1998. 124:24552.

32. Travaglino, E., Benatti, C., Malcovati, L., Porta, M. G. D., Gallì, A., Bonetti, E., Rosti V., Cazzola M., Invernizzi, R. Biological and clinical relevance of matrix metalloproteinases 2 and 9 in acute myeloid leukaemias and myelodysplastic syndromes. European Journal of Haematology, 2008. 80(3), 216-226. doi:10.1111/j.1600-0609.2007.01012.x. 
33. Visse, R., and Nagase, H. Matrix metalloproteinases and tissue inhibitors of metalloproteinases: structure, function, and biochemistry. Circ Res. 2003 92(8): 827-839. doi: 10.1161/01. RES.0000070112.80711.3D.

34. Wang D, Dubois RN. Eicosanoids and cancer. Nat Rev Cancer. 2010;10:181-193. doi: 10.1038/ nrc2809.

35. Yu F.X., Han Z.C. Matrix bone marrow metalloproteinases: gelatinase functions in physiological hematopoiesis and hematopoietic malignancies, Histol. Histopathelic. 21 Segment 2006, 519-531.

36. Zelenay, S., van der Veen, A. G., Böttcher, J. P., Snelgrove, K. J., Rogers, N., Acton, S. E., Reis e Sousa, C. Cyclooxygenase-Dependent Tumor Growth through Evasion of Immunity. Cell, 2015.162(6), 1257-1270. doi:10.1016/j. cell.2015.08.015. 